\title{
Changes in Craniovertebral Angle and Sagittal Shoulder Angle: Comparation between Modified Backpack and Conventional Backpack Users in 11- 12 Aged Boys
}

\author{
Theresia D Arini Leman, Ferial H Idris, Nyoman Murdana \\ Department of Physical Medicine and Rehabilitation, Faculty of Medicine - University of Indonesia, \\ Jakarta
}

\begin{abstract}
Objectives: to develop a better design of ergonomic backpack and to evaluate the effect of wearing conventional and modified backpack on CVA and SSA changes.

Methods: 34 male students of grade 5 and 6 elementary school who met the inclusion criteria (boys, 11-12 years old, normoweight, normoposture, and able to follow instruction) were included in the experimental and cross sectional studies to evaluate duration, time of complaint, and changes in CVA and SSA between the conventional and modified backpack groups; and subject preference to backpack design. This study was statistically analysed through Mann-Whitneym Wilcoxon, and Mc Nemar tests. Results: The modified backpack with two compartments, hip strap, compartment strap and wide shoulder strap gives more benefits. Majority of students preferred the modified design to conventional design. The modified design also gave students the ability to stand up longer. Narrowing CVA while wearing backpack was evident in conventional group $(n=25)$ in comparison with modified group $(n=15$, $\mathrm{p}=0.022)$. Moreover, narrowing SSA was also found more $(\mathrm{n}=18)$ in the conventional group than the modified group $(\mathrm{n}=4, \mathrm{p}=0.000)$.

Conclusions: Modified backpack design with two compartments, hip straps, wide shoulder straps, and compartment straps provides less CVA and SSA changes in comparison to conventional beckpack group. Minimal changes of CVA and SSA contributes to the development of a more ergonomic model of modified backpack to maintain postural stability.
\end{abstract}

Key Words: posture, craniovertebral angle, backpack, ergonomics.

\section{INTRODUCTION}

School-aged children experienced accelerating musculoskeletal development when growth spurth occurs. Any vertebral development problem would deteriorate postural integrity in the future. Carrying excess load, such as heavy backpack may result in disproportionate

Received in March 2013 and accepted for published in April 2013.

Correspondence Address: Theresia D. Arini Leman, J1. Taman Cilandak Raya No. C3, jakarta 12430. Email: theresia2710@gmail.com vertebral alignment. ${ }^{4,5}$

For about 7,277 patients per year visit the emergency room due to backpack carrying related trauma based on the data of Illinois State Board of Education. The number tends to increase as much as $330 \%$ since $1996 .{ }^{2}$ This happens when children exhibit intense compensation due to overweight backpack or excessive inclination to one side. A backpack study in Australia, Chansirinukorn et al found that postural changes, such as decreasing cervical lordosis appeared more in backpack user group who wore backpack weighed $15 \%$ of the body weight, compared to other group not 
wearing backpack. Decreasing cervical lordosis has strong relationship with high incident of neck muscle spasm and tension headache in adulthood. ${ }^{3,9,14,15,16,17,19,20,22}$

The aim of this study is to design the ergonomic backpack and to evaluate our hypothesis that modified backpack would cause minimal changes on cervical lordosis and shoulder position in comparison to conventional backpack.

\section{METHODS}

Design of this study consists of a) designing modified backpack which is ergonomic for school-aged children based on biomechanic theory; b) cross-sectional study to evaluate duration, complaint and preference subject of the backpack; and c) experimental study pre- and post design to test the hypothesis of the study.
Inclusion criteria of this study are boys, aged 11-12 years old, normal body weight, normal postur, and able to follow instruction. While the exclusion criteria consists of cardiorespiratory disease and any complaints of neck pain, upper or and lower back pain.

We adopt craniovertebral angle (CVA) and sagittal shoulder angle (SSA) for posture measurement. Craniovertebral Angle (CVA) is the angle formed at the intersection of a horizontal line through the spinous process of C7 and line of the tragus of the ear. This provides an estimation of neck on upper trunk positioning. Narrow angle indicates forward head posture. Sagittal Shoulder Angle (SSA) is formed through the intersection of $\mathrm{C} 7$ and the line between the mid point of greater tuberosity of humerus and the posteror aspect of acromion procress. This shows the measurement of forward shoulder position. ${ }^{5,17,19,21,22,23,24,25}$

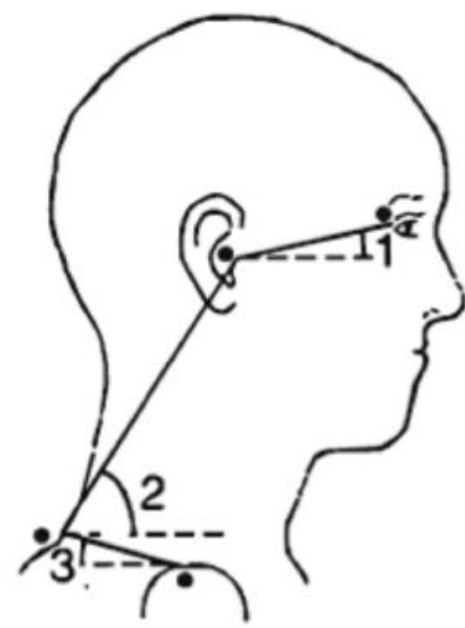

Figure 1. The craniohrizontal angle (1) and carniovertebral angle (2), and sagittal shoulder posture (3).

Conventional backpack:

Backpack dimension $23 \mathrm{~cm} \times 35 \mathrm{~cm} \times 10 \mathrm{~cm}$, made of polyester, consist of 1 compartment, 2 shoulder strap $4,5 \mathrm{~cm}$ width.

\section{Modified backpack:}

Backpack dimension $28 \mathrm{~cm} \times 35 \mathrm{~cm}$ x $13 \mathrm{~cm}$, made of polyester, consist of 2 compartments with compartment strap, curve-shaped, thick paded shoulder strap $6 \mathrm{~cm}$ width, hip strap $4 \mathrm{~cm}$ width, backpack equipped with soft padding. 


\section{Statistical analysis}

Mann-Whitney test is used to compare the complaint arised between the conventional backpack group and the modified backpack group. Wilcoxon test is employed to measure the backpack usage duration between the two groups. Lastly, Mc Nemar test is a comparison test of CVA and SSA between both groups.

\section{Procedure of the study}

Participants were those who agreed to parcipate and approved their informed consents independently. The CVA and SSA measurements were performed through the subject photographs. The photograph was taken from students wearing backpack between thoracal 1 (T1) and thoracal (T2) level.

Two photo sessions were carried out: At the first session, student was intructed to stand up without loading, followed by wearing a conventional backpack with load $15 \%$ of body weight for 10 minutes without changing the posture, then took a rest for one hour before continuing to wear a modified backpack for ten minutes; at the second session, which was on the following day, student was instructed to stand up without loading, followed by wearing a modified backpack with load $15 \%$ of body weight for ten minutes while standstill, then took rest for an hour, and end up by wearing a conventional backpack for ten minutes. The pictures were taken every 1 minute to observe any serial postural changes due to postural adaptation. The pictures were analyzed using digitalizing image program (Image Tool UTHCSA version 3.0 University of Texas Health Center, USA) for measurement of CVA and SSA.

\section{RESULTS}

Table 1 . Characteristics of the subject

\begin{tabular}{lcccc}
\hline & Minimum & Maximum & Mean & SD \\
\hline Age (years old) & 11 & 12 & 11.32 & 0.4 \\
Body weight $(\mathrm{kg})$ & 24 & 59 & 34 & 7.3 \\
Body height $(\mathrm{cm})$ & 127 & 156 & 140 & 7 \\
Shoulder width $(\mathrm{cm})$ & 30 & 40 & 33.7 & 2,3 \\
Trunk height $(\mathrm{cm})$ & 30 & 41 & 35.2 & 2,9 \\
\hline
\end{tabular}

\section{Duration in carrying backpack}

Table 2 shows the mean duration of subjects wearing a backpack in static standing position. In this position, subjects were not allowed to change or correct the position of the backpack.
In group with modified backpack, they could stand up as long as 0.5 minutes longer than the conventional backpack group, with $p=0.804$ (Wilcoxon test).

Table 2. Duration in Carrying Backpack up to Maximal Complaint

\begin{tabular}{lrrr}
\hline \multicolumn{1}{c}{ Variable } & Mean & SD & Med \\
\hline Duration carrying conventional backpack & 9.2 & 1.5 & 10.0 \\
Duration carrying modified backpack & 9.7 & 0.8 & 10.0 \\
\hline
\end{tabular}

$$
p=0.804 \text { (Wilcoxon) }
$$


Tabel 3. Subject Preference to Backpack

\begin{tabular}{lcc}
\hline \multicolumn{1}{c}{ Preference } & N & \% \\
\hline Modified & 29 & 85.3 \\
Conventional & 4 & 11.8 \\
Indifference & 1 & 2.9 \\
\hline Total & 34 & 100.0 \\
\hline
\end{tabular}

Table 4. Reason of Subject Preference to Modified Backpack

\begin{tabular}{lcc}
\hline \multicolumn{1}{c}{ Reason } & Conventional & Modified \\
\hline Comfortable & 3 & 8 \\
Light & 0 & 12 \\
Wide shoulder strap & 0 & 9 \\
No hip strap & 1 & 0 \\
\hline Total & 4 & 29 \\
\hline
\end{tabular}

Table 5. Distribution of Complaint Between Conventional and Modified Backpack Groups

\begin{tabular}{lcc}
\hline Complaint & N & (\%) \\
\hline Conventional backpack & 27 & 79.4 \\
Positive & 7 & 20.6 \\
$\quad \begin{array}{l}\text { Negative } \\
\text { Modified backpack }\end{array}$ & 17 & 50.0 \\
Positive & 17 & 50.0 \\
Negative & & \\
\hline
\end{tabular}

$p=0.013($ Mc Nemar test) 
Table 6. Time When Subjects Start to Complain

\begin{tabular}{cccc}
\hline Variable & Mean & & \\
& $($ minute-) & & \\
\hline Conventional backpack $(\mathrm{n}=27)$ & 4.9 & 1.7 & 5.0 \\
Modified backpack $(\mathrm{n}=20)$ & 5.6 & 3.0 & 6.5 \\
\hline$p=0.030$ (Mann-Whitney) &
\end{tabular}

\section{Changes in CVA after carrying Modified Backpack compared to Conventional Backpack}

We found that $73.5 \%$ of conventional backpack users experienced narrowing CVA, $14.7 \%$ showed relatively stable CVA, and $11.8 \%$ had widening CVA. Meanwhile, the modified backpack group showed $47.1 \%$ of users experienced narrowing CVA, $29.4 \%$ with relatively stable CVA, and $23.5 \%$ experienced widening CVA (Table 7).

Table 7. CVA Changes in Two Groups $(n=34)$

\begin{tabular}{lcc}
\hline \multicolumn{1}{c}{ CVA Changes } & N & \% \\
\hline Conventional backpack group & 25 & 73.5 \\
Narrow & 5 & 14.7 \\
Stable & 4 & 11.8 \\
$\quad$ Wide & & \\
Modified backpack group & 15 & 44.1 \\
Narrow & 13 & 38.2 \\
Stable & 6 & 17.6 \\
Wide &
\end{tabular}

\section{Changes in SSA after carrying Modified Backpack Compared to Conventional Backpack}

For about $47.1 \%$ of conventional backpack users experienced narrowing SSA, 29.4\% had relatively stable SSA, and $23.5 \%$ experienced widening SSA. On the other hand, the modified backpack group showed only $11.8 \%$ of narrowing SSA, $38.2 \%$ were relatively stable, and $50 \%$ with widening SSA (Table 8). 
Table 8. Overall Postural Changes

\begin{tabular}{lcc}
\hline \multicolumn{1}{r}{ Changes in SSA } & N & \% \\
\hline Conventional backpack group & 16 & 47.1 \\
Narrow & 10 & 29.4 \\
Stable & 8 & 23.5 \\
Wide & & \\
Modified backpack group & 4 & 11.8 \\
Narrow & 13 & 38.2 \\
Stable & 17 & 50 \\
Wide &
\end{tabular}

\section{DISCUSSION}

Participants who were male aged 11-12 years old are included because it is the period of growth spurt and any muscle imbalance will impair their future postural integrity. Moreover, boys have homogeinity property while girls at this age are susceptible to postural variation due to menarche and thelarche. ${ }^{3,4}$

This study found that most of complaint came from the conventional backpack group, such as back pain, fatigue and neck pain (Table 5). It is due to soft tissue tension and muscular imbalance. Subjects of modified backpack group began to complain later than the conventional as modified backpack have wider shoulder strap that causes less pressure on shoulder. In addition, most subjects preferred the modified backpack to conventional backpack because it provides less pressure to shoulder with its two compartments; and compartment, wide shoulder and hip straps; hence, gives wider load distribution and provides lighter backpack (Table 3, 4). Thus, subjects felt minimal pain and fatigue. . $^{35,36,37}$

Furthermore, modified backpack group demonstrated more stable CVA in comparison to conventional backpack group (Table 8). This is probably because of the even load distribution of the modified backpack design which results in postural stability. On the oher hand, conventional backpack model provides focus pressure at the posterior which leads the body to compensate the load through head forward leaning. $3,15,32,37,39,40$

Lastly, modified backpack group also showed more stable SSA which is probably due to comfortable design of wider shoulder strap that gives less pressure. ${ }^{3,15,16}$

\section{CONCLUSIONS}

In conclusion, the modified backpack design impinges the CVA and SSA less than the conventional backpack.

However, further studies are needed to improve the postural knowledge, identify the postural impairment and obtain solution to maintain good posture in children.

\section{REFERENCES}

1. Negrini S, Carabalona R. Backpacks on school children's perceptions of load, associations with back pain and factors determining the load. Spine. 2002;27:187-95. 
2. 1linois State Board of Education. Carrying Backpacks:Physical Effects. In: Education ISBo, editor.; June 2006.

3. Chansirinukor W, Wilson D, Grimmer $\mathrm{K}$, B D. Effects of backpacks on students: Measurement of cervical and shoulder posture. Australian Journal of Physiotherapy. 2001;47:110-6.

4. BF LeVeau DBB. Developmental biomechanics: effect of forces on the growth, development, and maintenance of the human body. Physical Therapy. 1984;64:1874-82.

5. Mayer T, Gatchel R, Polatin P. Occupational Musculoskeletal Disorders : Function, Outcomes, and Evidence. Philadelphia: Lippincott WIlliams \& WIlkins; 2000.

6. Neumann DA. Kinesiology of the Muskuloskeletal System. 1st ed. Missouri: Mosby; 2002. 7. Reyes T, Reyes O-L. Kinesiology. 1st ed. Manila: UST Printing Office; 1978.

8. Calliet R. Neck and arm pain. 3rd ed. Philadelphia: FA Davis Company; 1991.

9. Kroemer KHE, Grandjean E. Fitting the Task to the Human. London: Taylor and Francis; 1997.

10. Basmajian JV, DeLuca CJ. Muscles Alive. 5th ed. Baltimore Williams \& WIlkins; 1985.

11. Hamilton N. Kinesiology : Scientific Basic of Human Motion. 10th ed. New York: McGraw Hill; 2002.

12. Lovejoy CO. Evolution of human walking. Scientific American. 1988 November 1988:118-25.

13. LaFiandra $\mathrm{M}$, Obusek JP, Holt $\mathrm{KG}$, Wagenaar R. The Effect of Load Carriage on Trunk Coordination during Treadmill Walking at Increasing Walking Speed Meeting on "Soldier Mobility: Innovations in Load Carriage System Design and Evaluation"; 2000 2000; Kingston, Canada,; 2000.

14. Mayank Mohan US, Nishat Quddus. Effect of Backpack Loading on Cervical and Shoulder Posture in Indian School Children Indian Journal of Physiotherapy and Occupational Therapy. 2006;1:3-12.

15. Pascoe DD, Pascoe DE, Wang YT, al. e.
Influence of carrying book bags on gait cycle and posture of youths. Ergonomics. 1997;40:631-41.

16. Korovessis $\mathrm{PM}, \mathrm{PhD}$; Koureas, Georgios MD; Zacharatos, Spyridon MD; Papazisis, Zisis MD Backpacks, Back Pain, Sagittal Spinal Curves and Trunk Alignment in Adolescents: A Logistic and Multinomial Logistic Analysis. Spine. 2005;30(2):24755 .

17. Hodgson V R, Thomas L M. Mechanism of cervical spine injury during impact to the portected head. Proceedings of the 24th STAPP conference; 1980; Society of Automotive Engineers, Warrendale,PA; 1980. p. 17.

18. Scher AT. Serious cervical spine injury in the older rugby player : An indication for routine radiologic examination. S Afr Med J. 1983;64:138-40.

19. Jumah KB, Nyame PK. Relationship between load carrying on the head nd cervical spondylosis of Ghanians. West Afr J Med. 1994;13:101-2.

20. Chaffin PB, Andersson G. Occupational Biomechanics. New York: Wiley; 1984.

21. Kilbom A, Horst R. Observation Methods for reduction of load and strain an the human body : A review. Abetarskyoostyrelsen Publikation Service. 1986;171:92.

22. Harms-Ringdahl K, Schuldt K. Maximum neck extension strength and relative neck muscular load in different cervical spine positions. Clin Biomech. 1988;4:17-24.

23. Hong $\mathrm{Y}$, Cheung C-K. Gait and posture responses to backpack load during level walking in children Gait and Posture. 2003;17 28-33.

24. Hodgson V R H, AL, Thomas L MBarryGreb T, Wojtowicz. MechanismClinical measurements of cervical spine injury during impact to the portected head. and shoulder posture variables. Proceedings Journal of the 24th STAPP conference; 1980; 1980. p. 17.

25. Harrison A, Raine, S, Barry-Greb T, WojtowiczTwomey L. Clinical measurementsPosture of thehead and, shoulder posture variablesand thoracic spine in comfortable erect standing. 
Australian Journal of Orthopaedics and Sport Physical TherapyPhysiotherapy. 19961994;2340:353-36125-32.

26. Wilmarth A. Is your child's backpack making the grade? ; July 25, 2005. 57

27. Wickens J, Raine, S, Kiputh O, Twomey,L. Body mechanic analysisPosture of Yale University freshmen. the head, shoulder and thoracic spine in comfortable erect standing. Research QuarterlyAustralian Journal of Physiotherapy. 19371994;840:37-482532.

28. Youlian Hong CW, Chi-Kin Cheung Wilson D, Grimmer K, B D. GaitEffects of backpacks on students: Measurement of cervical and shoulder posture responses to backpack load during level walking in children. Gait and Posture Australian Journal of Physiotherapy. 20032001;1747:28 - 33110-116.

29. Grimmer KA, Williams, M. T., and Gill, T. $\mathrm{K}$. . The associations between adolescent lean-on neck posture, backpack weight, and anthropometric features. Spine. 1999;24(.):2262.

30. Troussier B, Davoine P, Gaudemaris D, Fauconnier, . Back pain in school children a study among 1178 pupils. . Scandinavian Journal of Rehabilitation Medicine. 1994;26:143-6.

31. Youlian Hong, Chi-Kin Cheung. Gait and posture responses to backpack load during level walking in children. Gait and Posture 2003;17:28 - 33 .

32. Mackie HW, S. J. Leggb, Beadlea J. Comparison of four different backpacks intended for school use. Applied Ergonomics. 2002 May 2003;34( 3):25764.
33. Fong DTP, Hong Y. The Effect of Load Carriage and School Bag Design on Lateral Trunk Posture during stairs descent in children.

34. Knapik J. Physiological, Biomechanical and Medical Aspects of Soldier Load Carriage Meeting on "Soldier Mobility: Innovations in Load Carriage System Design and Evaluation", ; 2002 27-29 June 2000,; Kingston, Canada, ; 2002.

35. Reid SA, Whiteside RA. Biomechanical Assessment of Lateral Stiffness Elements in the Suspension System of a Rucksack Meeting on "Soldier Mobility: Innovations in Load Carriage System Design and Evaluation" ; 2000 27-29 June 2000; Kingston, Canada; 2000.

36. Mannheimer JS, Rosenthal RM. Acute and chronic postural abnormalities as related to craniofacial pain and temporomandibular disorders. Dental Clinics of North America. 1991;35:185-208.

37. Obusek JP, Harman EA, N.Frykman P. The relationship of backpack center of mass location to the metabolic cost of load carriage. . Medicine and Science in Sports and Exercise. 1995.;29(5):S205.

38. Grimmer K. Reliability of upright posture measurement in primary school children. BMC Musculoskeletal Disorders. 200529 June 2005;6:35-44.

39. Raine S, Twomey L. Posture of the head, shoulder and thoracic spine in comfortable erect standing. Australian Journal of Physiotherapy. 1994;40:25-32.

40. Holewijn M. Physiological strain due to load carrying. European Journal of Applied Physiology,. 1990;61:237-45. 